\title{
Hot topic: Holder pasteurization of human milk affects some bioactive proteins
}

\author{
André F. Guerra, ${ }^{*}{ }^{1}$ Caroline Mellinger-Silva, $\ddagger$ Amauri Rosenthal, $\ddagger$ and Rosa H. Luchese* \\ *Department of Food Technology, Federal Rural University of Rio de Janeiro, 23.897-970 Seropédica, RJ, Brazil \\ †Federal Center of Technological Education Celso Suckow da Fonseca, 27.600-000 Valença, RJ, Brazil \\ łEmbrapa Food Technology, Guaratiba 23.020-470, Rio de Janeiro, RJ, Brazil
}

\begin{abstract}
The aim of this research was to investigate the effect of Holder pasteurization ( $\mathrm{HoP} ; 62.5^{\circ} \mathrm{C}, 30 \mathrm{~min}$ ) on the protein profile and activities of glutathione peroxidase (GPx) and lysozyme (LZ) in human milk. Over 6 mo of lactation, human milk samples were analyzed before (raw) and after HoP for GPx and LZ activity and electrophoresis protein profile. Holder pasteurization reduced human milk lactoferrin, immunoglobulin fractions, and GPx activity. In addition, GPx activity, which is high in colostrum and transitional milk, was naturally reduced over the 6 -mo lactation period. In contrast, HoP did not affect human milk LZ activity. Besides its critical cellular antioxidant role in protecting the organism from oxidative damage, GPx decreases the redox potential of milk, stimulating the growth of anaerobic microorganisms, such as the probiotic Bifidobacterium. Considering the role of lactoferrin in infant health, we conclude that an important part of its function has been inactivated by pasteurization. These compounds should be replaced by human milk banks after the HoP step to recover lost functionality. Otherwise, an alternative technology to HoP that better retains human milk properties should be used by milk banks to eliminate the risk of transmission of infectious agents.
\end{abstract}

Key words: bifidogenic factor, probiotic, health

\section{Hot Topic}

Human milk is perceived not only as a food but also as a dynamic biologic system. This complex fluid provides nutrients, bioactive compounds, and immune factors such as immunoglobulins, lactoferrin (Lf), and lysozyme (LZ). Feeding human milk is the best method to nourish and protect the newborn from infectious diseases (Tobback et al., 2017).

Received September 5, 2017.

Accepted January 3, 2018.

${ }^{1}$ Corresponding author: andrefioravanteguerra@gmail.com
Bioactive compounds from human milk, such as short-chain oligosaccharides, Lf, and LZ, promote the growth of beneficial gut microbiota, such as species of the genera Bifidobacterium and Lactobacillus (Thongaram et al., 2017). Sometimes, mothers discontinue breastfeeding soon after giving birth because milk is in short supply or unavailable and the infant cannot be nourished exclusively by this optimum source of nutrition (Kronborg et al., 2015). In this situation, human milk banks are essential, as they provide milk from donor mothers, which is a better alternative to infant formula. Safety of banked milk is ensured by Holder pasteurization (HoP), also called the LTLT method (low temperature, long time; $62.5^{\circ} \mathrm{C}$ for $30 \mathrm{~min}$ ). The pasteurization step is required to inactivate pathogenic bacteria and viruses, and it reduces spoilage to an acceptable level when delivery to health-impaired individuals or medical institutions is considered. However, heat treatment may reduce the content of some bioactive compounds in human milk (Lima et al., 2017).

Human milk may prevent many illnesses and diseases, such as ear infections, gastrointestinal infections, severe lower respiratory tract infections, atopic diseases (allergies, hay fever, asthma, and dermatitis), obesity, cardiovascular diseases, childhood leukemia, and sudden infant death syndrome (Lönnerdal, 2017; Moukarzel and Bode, 2017). Governments usually spend money treating these diseases, and these resources could be better applied to other health sectors. Additionally, gut colonization by Bifidobacterium and Lactobacillus is largely related to a well-functioning immune system, especially the production of $\operatorname{IgA}$, IgG, and IgM (Talja et al., 2014). Poor immunity is one of the main causes of childhood death. Improving the quality of the milk in human milk banks is essential to ensure a healthier life for the newborn and to reduce expenditure on disease treatment (Katke et al., 2015).

Unlike HTST treatment, HoP adversely affects bioactive compounds in human milk, including Lf (Klotz et al., 2017). Human milk is a dynamic enzymatic fluid, and pasteurization may cause protein denaturation (de Oliveira et al., 2016). Lactoferrin is an iron-binding 
glycoprotein, and its bacteriostatic and bactericidal effects on gram-positive and gram-negative bacteria are well known. It is known that some lactic acid bacteria, including probiotic bifidobacteria and lactobacilli, are resistant to its antibacterial effects. Moreover, Lfbinding protein in bifidobacteria is involved in growth stimulation mechanisms and it may play other roles (Oda et al., 2014).

Information about glutathione peroxidase (GPx) activity in prokaryotes is scarce. The GPX gene and GPx synthesis pathways have not been detected in anaerobes, including bifidobacteria. Lowering of the redox potential by GPx may stimulate the growth of bifidobacteria (Živković et al., 2015). Moreover, GPx may be depleted by heat treatment; therefore, pasteurization may also reduce the probiotic growth-promoting potential of human milk. Supplementation of glutathione to these bacteria may protect them from oxidative stress (Ladero and Sánchez, 2017); glutathione is also a sulfur and nutrient source.

The aim of this research was to investigate the effect of $\mathrm{HoP}$ on the protein profile and GPx and LZ activities in human milk. Activity of GPx was assessed and SDS-PAGE performed on 21 samples of breast milk taken from a healthy mother over a period of 6 mo after term delivery, with 3 to 4 collections each month. Lysozime activity was measured in 30 samples from the Human Milk Bank of IFF-Fernandes Figueira Institute (Rio de Janeiro, Brazil), collected by hand expression, and 2 others donated from voluntary healthy individuals that were collected with a breast pump. On all occasions milk was collected after nipples were cleaned with saline solution and a paper towel. The samples were immediately frozen to $-18^{\circ} \mathrm{C}$ and taken to the laboratory on ice. After thawing at $7^{\circ} \mathrm{C}$ for $9 \mathrm{~h}$, the milk was transferred in equal volumes to sterile test tubes.

Breast milk samples (1 $\mathrm{mL}$ of each sample) were pasteurized by the HoP method, according to the Human Milk Bank technical standards (Almeida, 2005). Samples were heat treated by immersion in a thermostatically controlled, stirred water bath. When the water temperature stabilized at $62.5^{\circ} \mathrm{C}$, the tubes were immersed in the bath so that the water level was 2 $\mathrm{cm}$ above the milk level. A tube containing the same amount of milk was used as a control, and a thermometer was inserted into the tube. The tubes were held in the water bath at pasteurization temperature for 30 min and shaken at regular intervals $(3 \mathrm{~min})$. Thereafter, samples were immediately cooled to $5^{\circ} \mathrm{C}$ in an ice bath and defatting by centrifugation at $21,000 \times$ $g$ (2K15, Sigma Laborzentrifugen, Osterode am Harz, Germany) for 10 min.

Glutathione peroxidase activity was measured in samples of raw and pasteurized milk (21 of each) from an individual donor by using a Glutathione Peroxidase Assay Kit (703102, Cayman Chemical, Ann Arbor, MI). A boiled milk sample was used as a negative control, in addition to the positive and negative controls provided with the assay kit. The reaction was started by addition of $20 \mu \mathrm{L}$ of cumene hydroperoxide to all wells, and the absorbance was read by using a plate reader (Uniscience, Multiskan FC, Thermo Scientific, Waltham, MA) at $340 \mathrm{~nm}$. After linear regression of time and absorbance values, the angular coefficient $(\triangle A C)$ was recovered and substituted into Equation [1] to calculate GPx activity:

$$
\text { GPx activity }=\frac{\Delta A C}{0.00373} \times \frac{0.19}{0.02},
$$

where $0.00373 \mu M^{-1}$ is the NADPH extinction coefficient adjusted for the path length of the solution in the well $(0.6 \mathrm{~cm})$ at $340 \mathrm{~nm}, 0.020 \mathrm{~mL}$ is the volume of diluted GPx (control) to 3 wells, and $0.19 \mathrm{~mL}$ is the final volume of the assay in all of the wells.

Defatted milk aliquots $(100 \mu \mathrm{L})$ were mixed with sample buffer $(200 \mu \mathrm{L})$ to obtain the protein electrophoresis profile and kept frozen $\left(-18^{\circ} \mathrm{C}\right)$ until use. Proteins were identified by SDS-PAGE analysis in a Bio-Rad vertical Mini-Protean Tetra Cell (Bio-Rad Laboratories, Hercules, CA). Stacking and running gels were prepared by using $8 \%$ (wt/vol) acrylamide solution. A 100-V electric current was used throughout the running time $(2.5 \mathrm{~h})$. Gels were stained with Coomassie Brilliant Blue. High- and low-molecular-weight standards from Bio-Rad Laboratories were added to calculate the protein masses (Laemmli, 1970).

Lysozyme activity was measured using the lysoplate method, with Micrococcus luteus [ATCC 4698; INCQS 356, Instituto Nacional de Controle de Qualidade em Saúde (INCQS) Culture Collection, Rio de Janeiro, Brazil] as indicator. Melted de Man, Rogosa, and Sharpe agar (Himedia, Mumbai, India) was inoculated with a fresh suspension of the indicator microorganism to a final concentration of approximately $10^{6} \mathrm{cfu} / \mathrm{mL}$ and plated in Petri dishes. Five wells were made in each plate with a sterile manual borer $(6.8 \mathrm{~mm}$ diameter $)$ and filled with $100 \mu \mathrm{L}$ of milk sample. After incubation of the plates at $36^{\circ} \mathrm{C}$ for $48 \mathrm{~h}$, the inhibition halo around each well's border was measured with a caliper.

Analysis of variance followed by Fisher test $(P>$ $0.05)$ and Tukey test $(P>0.05)$ was used to analyze significant differences among group means of GPx and lysozyme activity, respectively.

Holder pasteurization reduced the GPx activity of human milk, and we observed an additional natural reduction tendency in GPx concentration throughout 

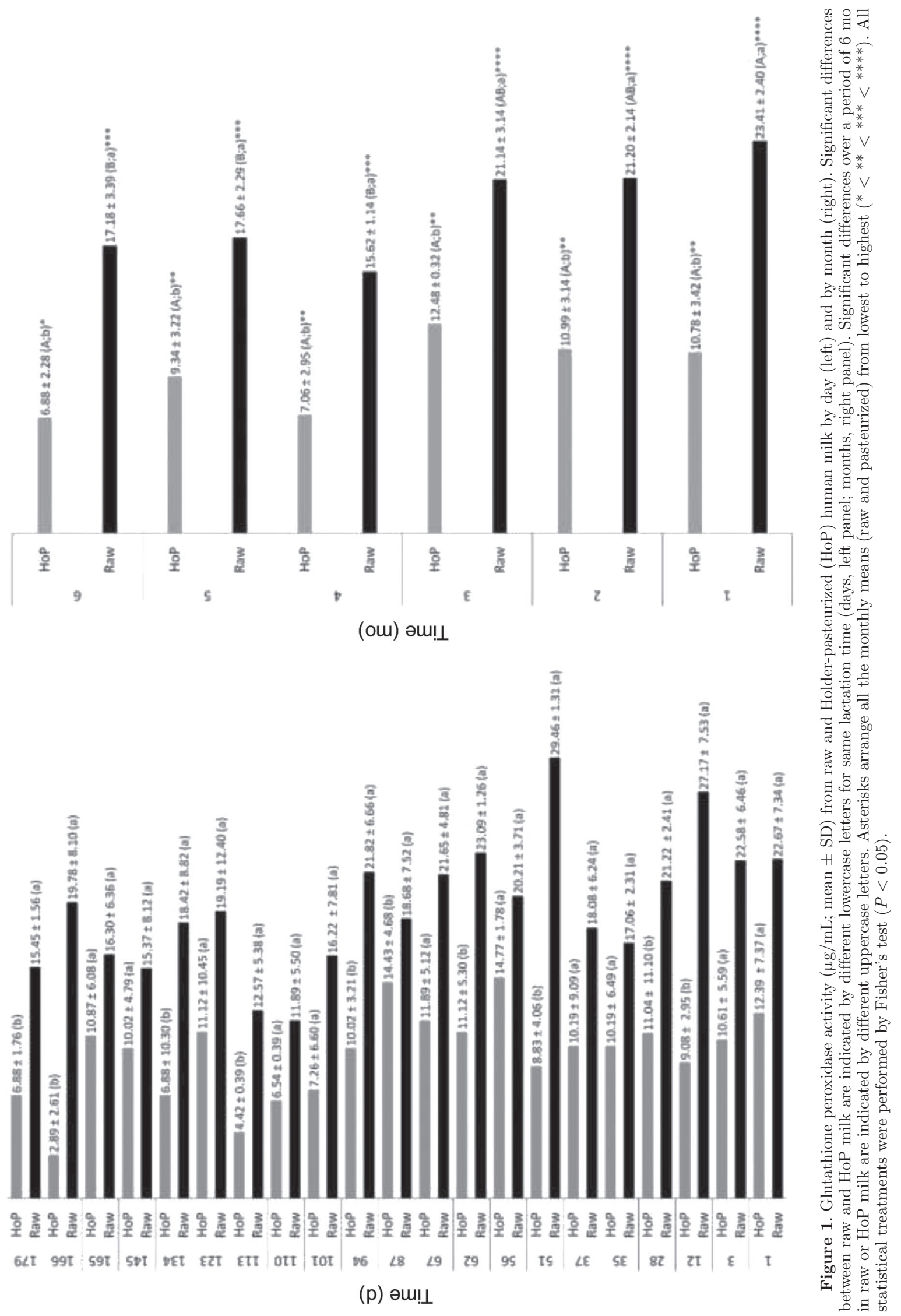
Table 1. Lysozyme activity (mean \pm SD) from 32 human milk samples before (raw milk) or after Holder pasteurization (HoP)

\begin{tabular}{|c|c|c|}
\hline \multirow[b]{2}{*}{ Sample number ${ }^{1}$} & \multicolumn{2}{|c|}{ Lysozyme activity $(\mu \mathrm{g} / \mathrm{mL})$} \\
\hline & Before HoP & After HoP \\
\hline 1 & $390.65 \pm 33.13$ & $392.86 \pm 3.83$ \\
\hline 2 & $225.01 \pm 11.48$ & $293.48 \pm 27.58$ \\
\hline 3 & $213.97 \pm 3.83$ & $213.97 \pm 3.83$ \\
\hline 4 & $183.05 \pm 44.11$ & $187.47 \pm 13.79$ \\
\hline 5 & $317.77 \pm 19.88$ & $328.81 \pm 3.83$ \\
\hline 6 & $\mathrm{ND}^{2}$ & $1.95 \pm 3.83$ \\
\hline 7 & $269.18 \pm 23.27$ & $213.97 \pm 15.30$ \\
\hline 8 & $251.52 \pm 17.53$ & $229.43 \pm 16.67$ \\
\hline 9 & $280.23 \pm 53.96$ & $222.80 \pm 19.13$ \\
\hline 10 & $304.52 \pm 19.88$ & $324.40 \pm 58.89$ \\
\hline 11 & $313.35 \pm 3.83$ & $260.35 \pm 21.30$ \\
\hline 12 & $266.97 \pm 20.24$ & $240.47 \pm 3.83$ \\
\hline 13 & $227.22 \pm 21.30$ & $242.68 \pm 13.79$ \\
\hline 14 & $200.72 \pm 7.65$ & $191.89 \pm 0.00$ \\
\hline 15 & $266.97 \pm 10.12$ & $278.02 \pm 36.89$ \\
\hline 16 & $194.09 \pm 10.12$ & $145.51 \pm 57.38$ \\
\hline 17 & $196.30 \pm 19.13$ & $130.05 \pm 21.30$ \\
\hline 18 & $269.18 \pm 13.79$ & $306.73 \pm 13.79$ \\
\hline 19 & $187.47 \pm 3.83$ & $238.26 \pm 13.25$ \\
\hline 20 & $1.95 \pm 3.83$ & $37.29 \pm 13.79$ \\
\hline 21 & $255.93 \pm 10.12$ & $253.72 \pm 3.83$ \\
\hline 22 & $244.89 \pm 28.88$ & $269.18 \pm 20.24$ \\
\hline 23 & $167.59 \pm 33.35$ & $180.84 \pm 42.08$ \\
\hline 24 & $308.94 \pm 10.12$ & $269.18 \pm 16.67$ \\
\hline 25 & $77.04 \pm 21.30$ & $26.25 \pm 17.53$ \\
\hline 26 & $269.18 \pm 25.08$ & $68.21 \pm 16.67$ \\
\hline 27 & $77.04 \pm 10.12$ & $79.25 \pm 23.89$ \\
\hline 28 & $116.80 \pm 36.49$ & $90.29 \pm 10.12$ \\
\hline 29 & ND & $6.37 \pm 0.00$ \\
\hline 30 & $202.93 \pm 13.79$ & $152.13 \pm 19.88$ \\
\hline D1 & $196.30 \pm 3.83$ & $158.76 \pm 26.50$ \\
\hline $\mathrm{D} 2$ & $278.02 \pm 17.53$ & $271.39 \pm 6.63$ \\
\hline Overall mean $\pm \mathrm{SD}$ & $225.16 \pm 80.95^{\mathrm{a}}$ & $197.06 \pm 100.47^{\mathrm{a}}$ \\
\hline
\end{tabular}

${ }^{a}$ Means with the same letter within a row are not significantly different by Tukey's test $(P>0.05)$.

${ }^{1}$ Samples 1-30 were obtained from the milk bank representing milks of different stages of lactation, and samples D1 and D2 are milks of mo 3 or 4 of lactation from 2 voluntary donors.

${ }^{2}$ Not detected; absence of lysozyme activity. the 6-mo lactation period. The rate of GPx decline increased after mo 3 of lactation in raw and HoP samples. The GPx activity in raw milk at the end of the 6-mo period was higher than that of pasteurized milk in mo 1 of lactation (Figure 1). Similar findings were observed by Marinković et al. (2016), who reported that pasteurization caused a significant decrease in the activity of the major antioxidative enzymes superoxide dismutase (SOD) and GPx.

Redox potential $\left(\boldsymbol{E}_{h}\right)$ of human milk is mainly due to SOD, catalase, and GPx activities; therefore, the change in $E_{h}$ correlates directly to the change in GPx activity. Antioxidative properties of human milk refer to the sum of activities derived from the active antioxidative enzymes SOD, glutathione (GSH) systemGPx and reductase; nonenzymatic antioxidants (such as ascorbate), and other bioactive factors (e.g., urate; Marinković et al., 2016). A low $E_{h}$ is necessary for growth, survival, and viability of bifidobacteria. Therefore, in addition to lowering the antioxidant activity in milk, the HoP process results in a loss of prebiotic activity in human milk (Fiser et al., 2015; Ladero and Sánchez, 2017). The best-known milk bifidogenic factors are galactooligosaccharides, which are not affected by HoP, but GPx may serve a prebiotic function, especially in early life.

The SDS-PAGE protein profiles were similar in raw and pasteurized milks, except for the amount of Lf (Figure 2), which decreased significantly $(P<0.05)$ in pasteurized milk over 6 mo of lactation. This reduction in LF was expected over the lactation period; however, it was more intense in pasteurized samples, perhaps due to protein denaturation, because denatured proteins were removed from the samples before the analysis. Lactoferrin is a glycoprotein with antimicrobial activity and is part of a nonspecific defense system in human milk. (Kaiser et al., 2017).
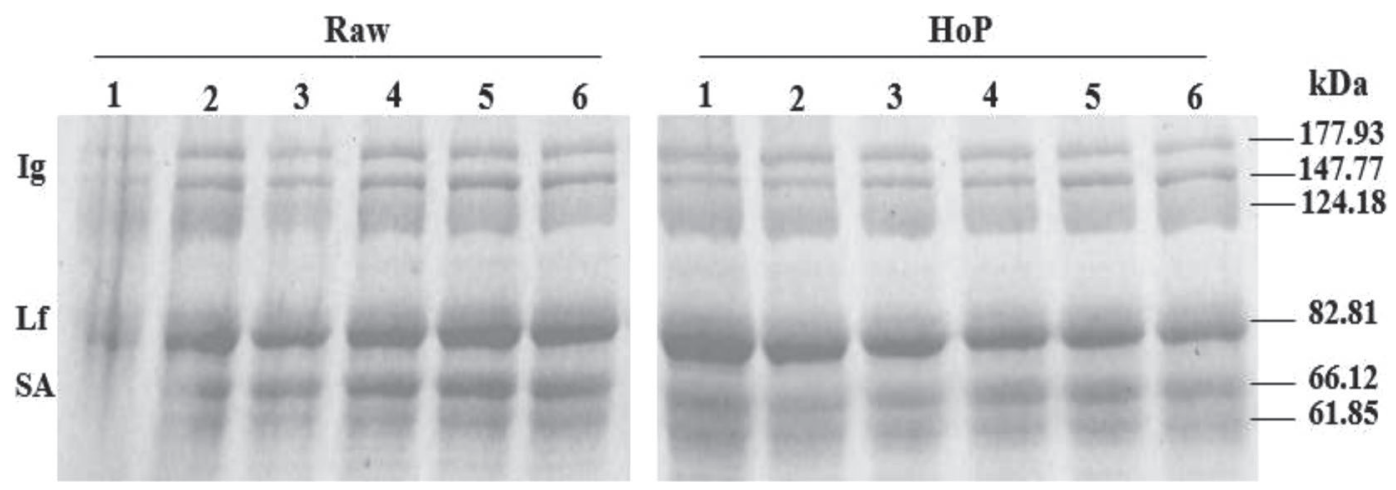

Figure 2. Sodium dodecyl sulfate-PAGE of raw and pasteurized (Holder-pasteurized, HoP) human milk proteins. Lf $=$ lactoferrin, SA $=$ human serum albumin. Lanes 1 to 6 indicate the month of lactation. 
Lysozyme activity was not affected by HoP (Table 1). However, Sousa et al. (2014) reported a reduction of LZ activity after HoP when using a turbidimetric method with Micrococcus luteus (ATCC 4698) as an indicator microorganism. Nevertheless, it is accepted that heating changes the conformation of LZ without affecting its antimicrobial activity. It is also known that LZ activity is dependent on ionic strength and $\mathrm{pH}$ (optimal 5.2). The turbidimetric procedure measures enzyme activity in up to 3 min of contact and may not reflect bioactivity in the human body.

Human milk banks should add bioactive compounds inactivated by HoP, such as GPx, to recover the lost functionality of milk following HoP. Although HoP does not affect LZ activity in human milk, it reduces the contents of $\mathrm{Lf}$ and immunoglobulins. It also reduces GPx activity, which is an important antioxidant that may play a role in modulating the gut microbiota of infants.

\section{ACKNOWLEDGMENTS}

This work was supported by CAPES (Coordination of Higher Education Foundation, Brasilia, DF, Brazil); CNPq (National Council for Scientific and Technological Development, Brasilia, DF, Brazil), and IFF (Fernandes Figueira Institute, Rio de Janeiro, RJ, Brazil).

\section{REFERENCES}

Almeida, J. A. G. 2005. Normas técnicas para bancos de leite humano. Fiocruz/IFF-BHL. 1-9. Rede Nacional de Bancos de Leite Humano, Rio de Janeiro, Brazil

de Oliveira, S. C., C. Bourlieu, O. Ménard, A. Bellanger, G. Henry, F. Rousseau, E. Dirson, F. Carrière, D. Dupont, and A. Deglaire. 2016. Impact of pasteurization of human milk on preterm newborn in vitro digestion: Gastrointestinal disintegration, lipolysis and proteolysis. Food Chem. 211:171-179.

Fiser, B., B. Jojart, M. Szori, G. Lendvay, I. G. Csizmadia, and B. Viskolcz. 2015. Glutathione as a prebiotic answer to alpha-peptide based life. J. Phys. Chem. B 119:3940-3947.

Kaiser, G. G., N. C. Mucci, V. González, L. Sánchez, J. A. Parrón, M. D. Pérez, M. Calvo, J. F. Aller, F. A. Hozbor, and A. A. Mutto.
2017. Detection of recombinant human lactoferrin and lysozyme produced in a bitransgenic cow. J. Dairy Sci. 100:1605-1617.

Katke, R., S. Walinjkar, M. Saraogi, and P. Tawre. 2015. Practicalities and benefits of human milk banks in India. Int. J. Gynaecol. Obstet. 129:83-84

Klotz, D., M. Joellenbeck, K. Winkler, M. Kunze, D. Huzly, and R. Hentschel. 2017. High-temperature short-time pasteurisation of human breastmilk is efficient in retaining protein and reducing the bacterial count. Acta Paediatr. 106:763-767.

Kronborg, H., I. Harder, and E. O. C. Hall. 2015. First time mothers' experiences of breastfeeding their newborn. Sex. Reprod. Healthc. $6: 82-87$.

Ladero, V., and B. Sánchez. 2017. Molecular and technological insights into the aerotolerance of anaerobic probiotics: Examples from bifidobacteria. Curr. Opin. Food. Sci. 14(Suppl. C):110-115.

Laemmli, U. K. 1970. Cleavage of structural proteins during the assembly of the head of bacteriophage T4. Nature 227:680-685.

Lima, H. K., M. Wagner-Gillespie, M. T. Perrin, and A. D. Fogleman. 2017. Bacteria and bioactivity in Holder pasteurized and shelf-stable human milk products. Curr. Develop. Nutr. 1:e001438. https://doi.org/10.3945/cdn.117.001438.

Lönnerdal, B. 2017. Bioactive proteins in human milk-Potential benefits for preterm infants. Clin. Perinatol. 44:179-191.

Marinković, V., M. Ranković-Janevski, S. Spasić, A. Nikolic-kokic, N. Lugonja, D. Djurović, S. Miletic, M. M. Vrvić, and I. Spasojevic. 2016. Antioxidative activity of colostrum and human milk. J. Pediatr. Gastroenterol. Nutr. 62:901-906.

Moukarzel, S., and L. Bode. 2017. Human milk oligosaccharides and the preterm infant. Clin. Perinatol. 44:193-207.

Oda, H., H. Wakabayashi, K. Yamauchi, and F. Abe. 2014. Lactoferrin and bifidobacteria. Biometals 27:915-922.

Sousa, S. G., I. Delgadillo, and J. A. Saraiva. 2014. Effect of thermal pasteurisation and high-pressure processing on immunoglobulin content and lysozyme and lactoperoxidase activity in human colostrum. Food Chem. 151:79-85.

Talja, I., A. L. Kubo, R. Veijola, M. Knip, O. Simell, J. Ilonen, M. Vaha-Makila, E. Sepp, M. Mikelsaar, M. Utt, and R. Uibo. 2014 Antibodies to Lactobacilli and Bifidobacteria in young children with different propensity to develop islet autoimmunity. J. Immunol. Res. 2014:325938.

Thongaram, T., J. L. Hoeflinger, J. Chow, and M. J. Miller. 2017. Human milk oligosaccharide consumption by probiotic and humanassociated bifidobacteria and lactobacilli. J. Dairy Sci. 100:78257833. https://doi.org/10.3168/jds.2017-12753

Tobback, E., K. Behaeghel, I. Hanoulle, L. Delesie, A. Loccufier, A. Van Holsbeeck, D. Vogelaers, and A. Mariman. 2017. Comparison of subjective sleep and fatigue in breast- and bottle-feeding mothers. Midwifery 47:22-27.

Živković, J., S. Sunarić, N. Trutić, M. Denić, G. Kocić, and T. Jovanović. 2015. Antioxidants and antioxidant capacity of human milk [Antioksidansi i antioksidativni kapacitet humanog mleka]. Acta Facultatis Medicae Naissensis 32:115-125. 